\title{
Primary autoimmune neutropenia of infancy and childhood in a cohort of patients from western Romania
}

\author{
CRISTIAN JINCA ${ }^{1}$, MARGIT SERBAN ${ }^{2}$, EMILIA URSU $^{2}$, ANDREI MUNTEANU $^{3}$ and SMARANDA ARGHIRESCU ${ }^{1}$ \\ ${ }^{1}$ Department of Pediatrics, ‘Victor Babes' University of Medicine and Pharmacy, 300041 Timisoara; \\ ${ }^{2}$ Department of Onco-Hematology, 'Louis Turcanu’ Emergency Hospital for Children, 300011 Timisoara; \\ ${ }^{3}$ Department of Puericulture and Neonatology, 'Victor Babes' University of Medicine and Pharmacy, 300041 Timisoara, Romania
}

Received September 18, 2020; Accepted October 19, 2020

DOI: $10.3892 /$ etm.2021.9711

\begin{abstract}
Neutropenia is commonly diagnosed in pediatric clinics. Due to the special vulnerability of neutropenic patients, the assessment of the etiopathogenic background of neutropenia is mandatory. In this retrospective cross-sectional cohort study, we aimed to establish the status of primary autoimmune neutropenia (AIN) from the point of view of its clinical and biological features and its outcome in a cohort of pediatric patients. We recorded all of the 3,488 cases consecutively admitted to our hospital for different diagnoses but presenting neutropenia, during a period of 3 years (January 2016 to December 2018). We had to exclude 224 patients from the analysis due to incomplete data. Our study focused on patients with AIN or chronic benign neutropenia of infancy and childhood. In these patients, a granulocyte antibody screening by granulocyte immunofluorescence test (GIFT) and the granulocyte agglutination test (GAT) were performed. Regarding their pathogenic background, $0.1 \%$ of the patients presenting neutropenia were congenital forms, the rest being acquired forms. Primary AIN was encountered in 18 cases, representing approximately $0.5 \%$. The median age at onset for primary AIN was 7.5 months. Male/female ratio in AIN was 1.94 . In $72 \%$ of the patients with AIN, neutropenia was severe during the course of disease. In 3 patients, both GIFT and
\end{abstract}

Correspondence to: Dr Cristian Jinca, Department of Pediatrics, 'Victor Babes' University of Medicine and Pharmacy; Piaţa Eftimie Murgu nr. 2, 300041 Timisoara, Romania

E-mail: cristian_jinca@yahoo.com

Abbreviations: AIN, autoimmune neutropenia; ANC, absolute neutrophil count; $\mathrm{BM}$, bone marrow; $\mathrm{CN}$, cyclic neutropenia; $\mathrm{CMV}$, cytomegalovirus; CBC, complete blood count; CRP, C-reactive protein; EBV, Epstein-Barr virus; EDTA, ethylenediaminetetraacetic acid; ESR, erythrocyte sedimentation rate; GAT, granulocyte agglutination test; G-CSF, granulocyte-colony stimulating factor; GIFT, granulocyte immunofluorescence test; HNA, human neutrophil antigen; MAIGA, monoclonal antibody-specific immobilization of granulocyte antigen; SCN, severe congenital neutropenia; UTI, urinary tract infection

Key words: autoimmune neutropenia, granulocyte immunofluorescence test, granulocyte agglutination test, human neutrophil antigen, granulocyte antibody screening
GAT were positive and in 8 patients, only GIFT was positive. For the remaining 7 patients (39\%), both GIFT and GAT revealed negative results. $50 \%$ of the patients needed hospitalization, but only 3 patients presented severe infections. On-demand G-CSF was administered in $22 \%$ of the patients. Our study provides insight with regard to neutropenia, showing the high frequency and etiological diversity in childhood. Primary AIN is usually diagnosed by exclusion of the other causes of neutropenia. GIFT and GAT are useful, but rarely available diagnostic tools for the confirmation of primary AIN.

\section{Introduction}

Neutropenia is defined by a reduced absolute neutrophil count (ANC). In Caucasian infants, aged between 2 weeks and 1 year, the lower limit of the ANC is $1,000 / \mu 1$, whereas for children above the age of 1 year, the lower limit of the ANC is $1,500 / \mu 1$. Frequently encountered in children, the disorder may be responsible for various clinical representations, from benign and transient forms to sometimes overwhelming disease $(1,2)$. Mild neutropenia is defined by an ANC between $1,000-1,500 / \mu 1$, moderate by $500-1,000 / \mu 1$ and the severe form by $\mathrm{ANC}<500 / \mu \mathrm{l}$ (3). Autoimmune neutropenia (AIN), a special form of the disorder, is due to autoantibodies against neutrophil-specific cell surface antigens, such as the human neutrophil antigen (HNA)-1a, HNA-1b and HNA-2. Antibody-coated neutrophils are destroyed in the peripheral blood, sometimes augmented by deposition of C3 complement fraction. The anti-neutrophil antibodies may also interfere with myelopoiesis in the bone marrow (4). Historically, its prevalence is considered to be $1 / 100,000$ in children under the age of 10 , consequently belonging to a group of rare disorders. It is part of the large and heterogeneous group of neutropenias, some of intrinsic origin (mainly congenital, mostly a result of altered myelopoiesis) and various others with extrinsic determination (acquired, primary or secondary to altered myelopoiesis, malignancy, drugs, infections). AIN itself can have a heterogeneous background, as an isolated disorder (primary AIN) or occurring within the frame of other autoimmune diseases and even as a complication of infections, drugs, malignancy or vaccination (secondary AIN). The identification of primary AIN, also named chronic benign neutropenia of infancy and childhood, within the large and heterogeneous group of neutropenias, is of utmost importance, if we consider 
the risk of sometimes overwhelming life-threatening infections on the one hand and the expensive therapies (prophylactic G-CSF replacement, antibiotic prophylaxis) on the other hand, which could and should be avoided. Primary AIN of infancy and childhood usually has a harmless and self-limited clinical course, with low frequency and severity of infections, easily managed in an outpatient setting; although some cases, mainly young infants, may suffer from severe infection $(1,3,5)$. Our objectives were to review the clinical and biological features, as well as the outcome of primary AIN in a cohort of pediatric patients and to assess the role of anti-neutrophil antibody screening in confirming and decision-making of the therapeutic and follow-up approach.

\section{Patients and methods}

This retrospective, cross-sectional cohort study was performed on 18 patients with primary AIN, selected out of 3,488 patients consecutively admitted to the 'Louis T,urcanu' Emergency Hospital for Children, with different diagnoses, but who also developed neutropenia. The retrospective enrollment period was 3 years (January 2016 to December 2018). We had to exclude 224 patients from the analysis due to incomplete data. From the remaining 3,264 patients, we focused on patients with primary AIN of infancy. The approval of the local ethics committee, Ethics Committee for Scientific Research of the Emergency Hospital for Children 'Louis Turcanu' (approval no. 77/2020), was obtained prior to starting the study. Patient's parental or caregiver's consents were obtained where applicable.

Primary AIN of infancy and childhood represented around $0.5 \%$ of all cases (18 patients). In order to be included in the study, patients had to fulfill the criteria for neutropenia (ANC $<1,500 / \mu 1$ for children $>1$ year of age, ANC $<1,000 / \mu$ l for infants aged over 2 weeks); and more than 3 months persistence of neutropenia and granulocyte antibody screening performed. Exclusion criteria were: underlying disorders that could render neutropenia as secondary and patients with incomplete data or lost to follow-up.

The granulocyte antibody screening consisted of the granulocyte immunofluorescence test (GIFT), which detects autoantibodies bound to patient neutrophils or in patient plasma and the granulocyte agglutination test (GAT), which is used to detect agglutination of control neutrophils in contact with sensitized patient serum sample. For GIFT, paraformaldehyde-fixed neutrophils are incubated with serum to allow neutrophil reactive antibodies to bind to the antigenic epitopes and then washed and incubated with a fluorescence-labeled anti-human globulin IgG, IgM and IgA. Fluorescence microscopy is used for the analysis. In the GAT, neutrophil-reactive antibodies bind to native antigens on unfixed neutrophils, sensitizing the cells followed by a second phase; sensitized neutrophils undergo chemotaxis and move towards other neutrophils and agglutinate. The screening was performed by means of both the GIFT test and the GAT test, in compliance with the recommendations of the Second International Granulocyte Serology Workshop (6).

For the anti-neutrophil antibody screen, $6 \mathrm{ml}$ of blood in EDTA vacutainers and $4 \mathrm{ml}$ of non-anticoagulated blood were drawn from each patient after prior approval by their parents or caregivers. The workup of all patients also included: Complete blood count $(\mathrm{CBC})$ with differentials and reticulocyte count, peripheral blood smear, biochemistry including C-reactive protein (CRP), erythrocyte sedimentation rate (ESR), ferritin, transaminases
Table I. Distribution of the patients by type of neutropenia $(\mathrm{N}=3,264)$.

Type of neutropenia No. of patients $(\%)$

Autoimmune (primary and secondary)

Congenital neutropenia

Neutropenia of prematurity

Bone marrow failure syndromes

Neutropenia in malignancy and

205 (6.3)

chemotherapy

Transient neutropenia

$2,955(90.45)$

Table II. Types of secondary AIN (N=13).

Type of secondary AIN

No. of patients

Systemic lupus erythematosus 5

Autoimmune lymphoproliferative syndrome 1

Hemophagocytic lymphohistiocytosis

1

Wiskott-Aldrich syndrome

2

IgA deficiency

1

Fanconi anemia associated with autoimmunity 3

AIN, autoimmune neutropenia.

and lactate dehydrogenase (LDH), and immunological screening with quantitative IgG, IgM and IgA measurement, complement $\mathrm{C} 3$ and $\mathrm{C} 4$, anti-nuclear antibody screen, serological markers for cytomegalovirus (CMV), Epstein-Barr virus (EBV), hepatitis $\mathrm{B}$, and $\mathrm{C}$, human immunodeficiency virus (HIV) and toxoplasmosis. Hematological investigations were performed with a Sysmex XS800i analyzer (SYSMEX Corp., Kobe, Japan) using impedance spectroscopy, flow cytometry, Hydro Dynamic Focusing (DC Detection method). The biochemical investigations were performed with a Cobas Integra 400 Plus analyzer (ROCHE Diagnostics GmbH, Germany). Bone marrow (BM) smear examination was also performed in some patients. Data were collected and analyzed from the patient files by means of a database in Microsoft Office Excel software. Descriptive statistics, correlations and Kaplan-Meier curves were performed using IBM $^{\circledR}$ SPSS $^{\circledR}$ statistics version 25 (IBM Corp.). A P-value of $<0.05$ was considered to be significant.

\section{Results}

The median age at onset of neutropenia of any type was 3 months (range 0-9 months) and for children aged over 1 year, 3.5 years (range 1-17.9 years). The distribution of the types of neutropenia are documented in Table I.

Autoimmune neutropenia (primary and secondary) represented approximately $1 \%$ of the 3,264 patients enrolled in the analysis, being found in 31 patients. From these patients, 18 were diagnosed with primary AIN of infancy and childhood. The rest of the patients (13) presented secondary AIN (Table II). Our study focused on the 18 patients with primary AIN. 
Table III. Characteristics of the study patients, and results of the granulocyte antibody screening and outcome.

\begin{tabular}{|c|c|c|c|c|c|}
\hline Pt. no & $\begin{array}{l}\text { Age at } \\
\text { diagnosis } \\
\text { (months) }\end{array}$ & $\begin{array}{l}\mathrm{ANC} / \mu 1 \text { at } \\
\text { diagnosis }\end{array}$ & $\begin{array}{l}\text { Severity of neutropenia } \\
\text { (minimal ANC during } \\
\text { course of disease) }\end{array}$ & Anti-neutrophil antibody screening & $\begin{array}{l}\text { Outcome (time } \\
\text { to resolution) }\end{array}$ \\
\hline 1 & 7 & 120 & Severe $(\min 0 / \mu 1)$ & $\begin{array}{l}\text { GIFT positive with } 2 \text { out of } 4 \text { test cells/GAT } \\
\text { weak positive with } 4 \text { out of } 4 \text { test cells }\end{array}$ & 23 months \\
\hline 2 & 3 & 730 & Severe $(\min 0 / \mu 1)$ & $\begin{array}{l}\text { GIFT weak positive with } 3 \text { out of } 4 \text { test } \\
\text { cells/GAT negative with } 4 \text { out of } 4 \text { test cells }\end{array}$ & $>15$ months \\
\hline 3 & 9 & 70 & Severe $(\min 70 / \mu 1)$ & $\begin{array}{l}\text { GIFT positive with } 4 \text { out of } 4 \text { test cells/GAT } \\
\text { positive with } 2 \text { out of } 3 \text { test cells }\end{array}$ & 12 months \\
\hline 4 & 11 & 100 & Severe $(\min 30 / \mu 1)$ & $\begin{array}{l}\text { GIFT positive for anti-IgG with } 3 \text { out of } 4 \\
\text { test cells, GIFT negative for anti-IgM with } \\
2 \text { out of } 2 \text { test cells/GAT positive at } 30^{\circ} \mathrm{C} \\
\text { with } 4 \text { out of } 4 \text { test cells, GAT negative } \\
\text { at } 37^{\circ} \mathrm{C} \text { with } 4 \text { out of } 4 \text { test cells }\end{array}$ & 18 months \\
\hline 5 & 5 & 130 & Severe $(\min 0 / \mu 1)$ & $\begin{array}{l}\text { GIFT negative with } 4 \text { out of } 4 \text { test } \\
\text { cells/GAT negative with } 4 \text { out of } 4 \text { test cells }\end{array}$ & 26 months \\
\hline 6 & 8 & 70 & Severe $(\min 0 / \mu 1)$ & $\begin{array}{l}\text { GIFT positive with } 3 \text { out of } 4 \text { test cells/GAT } \\
\text { negative with } 2 \text { out of } 2 \text { test cells }\end{array}$ & 13 months \\
\hline 7 & 3 & 800 & Moderate $(\min 630 / \mu 1)$ & $\begin{array}{l}\text { GIFT negative with } 4 \text { out of } 4 \text { test } \\
\text { cells/GAT negative with } 4 \text { out of } 4 \text { test cells }\end{array}$ & 7 months \\
\hline 8 & 8 & 200 & Severe $(\min 70 / \mu 1)$ & $\begin{array}{l}\text { GIFT clearly positive with } 1 \text { out of } 3 \text { test } \\
\text { cells/GAT negative with } 3 \text { out of } 3 \text { test cells }\end{array}$ & 5 months \\
\hline 9 & 20 & 90 & Severe $(\min 40 / \mu 1)$ & $\begin{array}{l}\text { GIFT strong positive with } 4 \text { out of } 4 \text { test } \\
\text { cells/GAT negative with } 4 \text { out of } 4 \text { test } \\
\text { cells/LIFT negative with } 4 \text { out of } 4 \text { test cells }\end{array}$ & 18 months \\
\hline 10 & 10 & 0 & Severe $(\min 0 / \mu 1)$ & $\begin{array}{l}\text { GIFT weak to strong positive with } 3 \text { out of } \\
4 \text { test cells/GAT negative with } 4 \text { out of } \\
4 \text { test cells/LIFT negative with } 4 \text { out of } 4 \text { test } \\
\text { cells/Glycoprotein specific immune assay } \\
\text { to CD11a, CD11b, CD16b, CD18, CD117, } \\
\text { HLA-class I antigen }\end{array}$ & 18 months \\
\hline 11 & 8 & 0 & Severe $(\min 0 / \mu 1)$ & $\begin{array}{l}\text { GIFT negative with } 4 \text { out of } 4 \text { test } \\
\text { cells/GAT negative with } 4 \text { out of } 4 \text { test cells }\end{array}$ & 14 months \\
\hline 12 & 1 & 700 & Moderate $(\min 700 / \mu 1)$ & $\begin{array}{l}\text { GIFT negative with } 4 \text { out of } 4 \text { test } \\
\text { cells/GAT negative with } 4 \text { out of } 4 \text { test cells }\end{array}$ & 9 months \\
\hline 13 & 1 & 800 & Severe $(\min 430 / \mu 1)$ & $\begin{array}{l}\text { GIFT weak positive with } 3 \text { out of } 4 \text { test } \\
\text { cells (anti-HNA1a)/GAT negative with } \\
4 \text { out of } 4 \text { test cells }\end{array}$ & 13 months \\
\hline 14 & 3 & 620 & Severe $(\min 410 / \mu 1)$ & $\begin{array}{l}\text { GIFT weak positive with } 4 \text { out of } 4 \text { test } \\
\text { cells/GAT negative with } 4 \text { out of } 4 \text { test cells }\end{array}$ & 16 months \\
\hline 15 & 11 & 430 & Severe $(\min 0 / \mu 1)$ & $\begin{array}{l}\text { GIFT negative with } 4 \text { out of } 4 \text { test } \\
\text { cells/GAT negative with } 4 \text { out of } 4 \text { test cells }\end{array}$ & 5 months \\
\hline 16 & 6 & 640 & Severe $(\min 460 / \mu 1)$ & $\begin{array}{l}\text { GIFT weak positive with } 3 \text { out of } 4 \text { test } \\
\text { cells/GAT negative with } 4 \text { out of } 4 \text { test cells }\end{array}$ & 12 months \\
\hline 17 & 7 & 780 & Severe $(\min 250 / \mu 1)$ & $\begin{array}{l}\text { GIFT negative with } 4 \text { out of } 4 \text { test } \\
\text { cells/GAT negative with } 4 \text { out of } 4 \text { test cells }\end{array}$ & 8 months \\
\hline \multirow[t]{2}{*}{18} & 15 & 540 & Moderate $(\min 540 / \mu 1)$ & $\begin{array}{l}\text { GIFT negative with } 4 \text { out of } 4 \text { test } \\
\text { cells/GAT negative with } 4 \text { out of } 4 \text { test cells }\end{array}$ & 8 months \\
\hline & $\begin{array}{l}\text { Median } \\
7.5 \text { months }\end{array}$ & $\begin{array}{l}\text { Median } \\
315 / \mu 1\end{array}$ & Median $55 / \mu 1$ & & $\begin{array}{l}\text { Median } \\
13 \text { months }\end{array}$ \\
\hline
\end{tabular}

ANC, absolute neutrophil count; GIFT, granulocyte immunofluorescence test; GAT, granulocyte agglutination test; LIFT, lymphocyte immunofluorescence test. 
Table IV. Clinical manifestations and reasons for examination at the time of diagnosis $(\mathrm{N}=18)$.

\begin{tabular}{lc} 
Reason for presentation at diagnosis & No. of patients (\%) \\
\hline Evaluation for anemia & $3(16.9)$ \\
Rhinopharyngitis & $3(16.9)$ \\
Ethmoiditis & $1(5.5)$ \\
Enterocolitis & $2(11.2)$ \\
Urinary tract infection & $1(5.5)$ \\
Pneumonia & $1(5.5)$ \\
Neonatal omphalitis & $1(5.5)$ \\
Asymptomatic (routine analysis) & $6(33)$ \\
\hline
\end{tabular}

Most patients with primary AIN had their first diagnosis during infancy, the median age at diagnosis being 7.5 months (range 1-20 months). The male/female ratio was 1.94. Regarding the severity of neutropenia at first diagnosis, we found that 10 patients $(56 \%)$ presented severe neutropenia and 8 patients (44\%) moderate neutropenia. Median ANC at diagnosis was $315 / \mu 1$ (range $0-800 / \mu 1$ ). In contrast, during the course of the disease, 13 patients (72\%) presented ANC counts below $500 / \mu 1$, whereas only 5 patients stabilized at ANC between $500-1,000 / \mu 1$. Table III presents the main characteristics of the 18 study patients and the results of the granulocyte antibody screening.

Regarding the clinical manifestations at diagnosis, 6 patients (33\%) were asymptomatic, neutropenia being revealed by a routine analysis. Table IV depicts the reasons for presentation of the patients at initial diagnosis.

Bone marrow (BM) examination was performed in 8 patients (45\%). In 6 cases, the marrow smears revealed a bone marrow sample with rich cellularity and moderate myeloid hyperplasia. In patient no. 2 (Table III), the smear showed hypoplasia of the myeloid series with delayed maturation and hypoplasia of the erythroblastic series and moderate lymphocytosis. The patient presented a positive GIFT test and did not recover yet, after 15 months of follow-up. Patient no. 11 (Table III), whose BM examination also revealed a hypoplastic marrow, especially of the myeloid series, with stimulation of the cellular immunocompetent system and moderate stimulation of the erythropoiesis, had a negative antibody screening, but recovered spontaneously at 14 months after diagnosis.

Granulocyte antibody screening was performed in all 18 patients. In 8 patients (45\%), GIFT was positive, but GAT was negative. In 3 patients (16\%), both GIFT and GAT yielded positive results, whereas in 7 patients (39\%) both GIFT and GAT revealed negative results. Table III depicts the results of each patient. In all patients with positive GAT test, results were confirmed by the GIFT test.

During the course of the disease, within the follow-up period, 16 patients (89\%) presented upper respiratory tract infections, the majority of which were uncomplicated rhinopharyngitis. Otitis media occurred in 3 patients, one of which presented recurrent otitis. Two patients presented pneumonia and other 2 urinary tract infections (UTI). Three patients developed enterocolitis, one of which was due to rotavirus infection. One patient presented

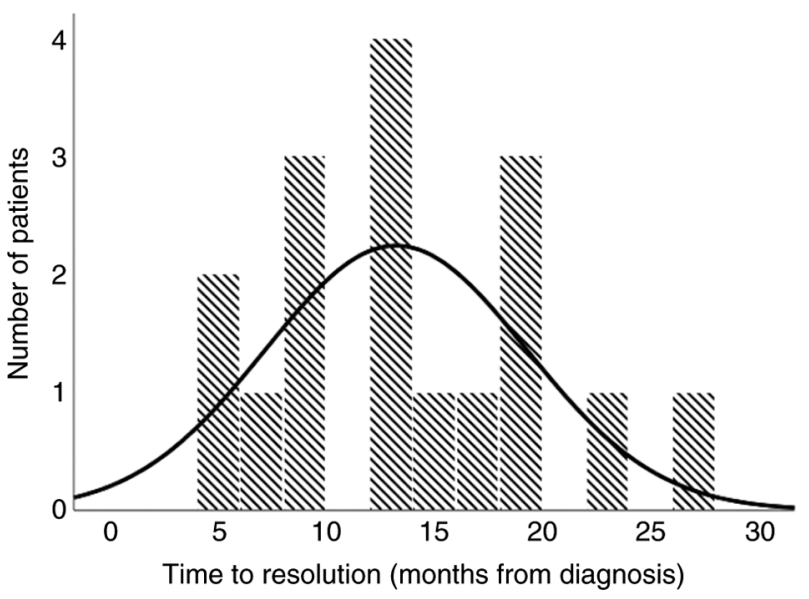

Figure 1 . Time to recovery of neutropenia.

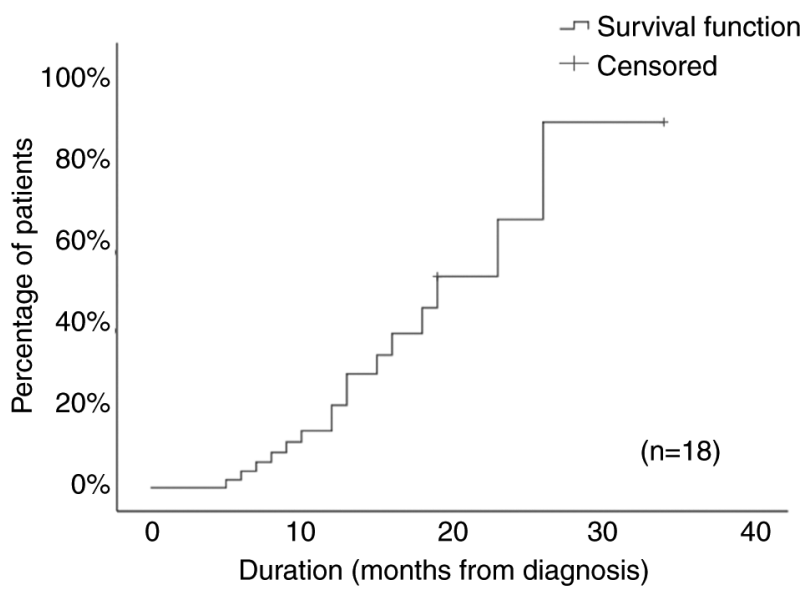

Figure 2. Kaplan-Meier recovery curve of neutrophils.

omphalitis with $E$. coli, this being the initial clinical finding at admission. The clinical follow-up of the patients showed that in 3 cases (17\%), the clinical course of the disease was severe with the need for aggressive antibiotic therapy, the patients presenting pneumonia and ethmoiditis. Nevertheless, $50 \%$ of the patients required hospitalization for neutropenic fever and/or proven bacterial infection, but no patient needed antibiotic prophylaxis and the outcome of infections was in all cases favorable. None of the patients developed systemic or localized fungal infections, except for oral thrush, which was treated topically. Eleven patients (61\%) required antibiotic therapy during the course of the disease or during the follow-up period and in 4 patients (22\%), a short course of low-dose G-CSF was used during infectious episodes. Intravenous immunoglobulin ( $\mathrm{IvIg}$ ) was administered in one patient and it was very efficient, inducing permanent remission of the AIN (Table V).

The median time to recovery of neutropenia was 13 months (range 5-26 months), as shown in Fig. 1. In 89\% of the patients, the time to recovery from neutropenia was within 20 months after diagnosis. Fig. 2 depicts the Kaplan-Meier recovery curve for the study cohort. The pattern of neutrophil recovery was intermittent, with alternating phases of normalization and relapse in 5 patients $(28 \%)$ and continuous in the other $13(72 \%)$. 
Table V. Characteristics of infections during the course of disease.

\begin{tabular}{lcc}
\hline Parameter & No. of patients $(\%)$ & Observation \\
\hline Severe infections & $3(17)$ & Pneumonia, ethmoiditis \\
Need for infection-driven hospitalization & $9(50)$ & Fever and/or proven bacterial infection \\
Fungal infections & $0(0)$ & Exception: Oral thrush topical treatment \\
Favorable outcome & $18(100)$ & \\
Antibiotic prophylaxis & $0(0)$ & \\
Antibiotic use during hospitalization or home treatment & $11(61)$ & Short course/low-dose \\
Use of G-CSF (on-demand) & $4(22)$ & Induced permanent remission \\
Use of IvIg & $1(5.5)$ & \\
\hline
\end{tabular}

G-CSF, granulocyte-colony stimulating factor; IvIg, intravenous immunoglobulin.

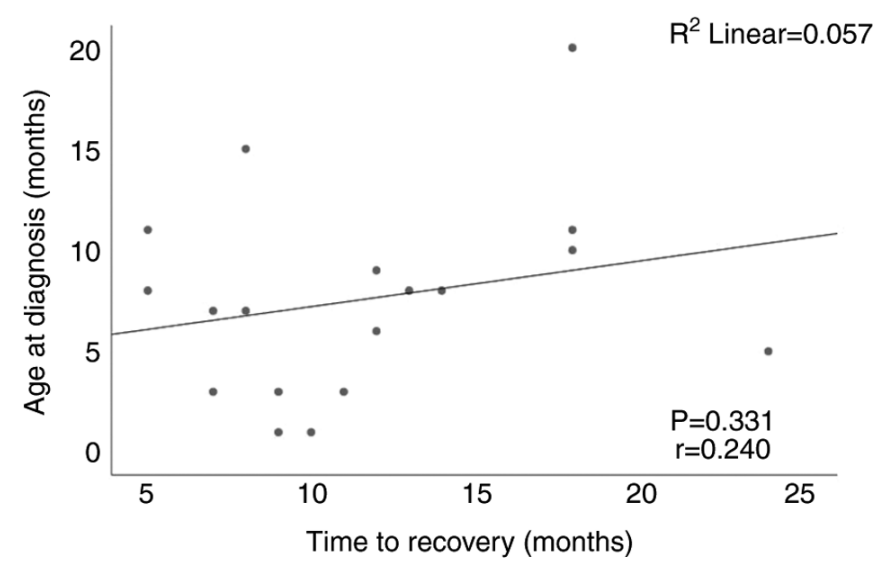

Figure 3. Correlation between age at diagnosis and time to recovery.

One of the objectives of the study was to establish if age at diagnosis correlates with the time to recovery. Fig. 3 shows that there was no statistically significant correlation $(\mathrm{r}=0.240$, $\mathrm{P}=0.331$ ) between the two variables.

\section{Discussion}

In our observational study, we present the clinical and biological features of 18 patients with primary autoimmune neutropenia (AIN) starting from the premise that all types of neutropenia are frequent in infancy and early childhood but the persistent, chronic forms are rare. Within the frame of multiple etiologies and mechanisms involved in the pathological background of neutropenia, the diagnosis of primary AIN of infancy remains one of exclusion. The diagnosis is often suggested by the benign course of the disease, rarely severe, despite the impressively low absolute neutrophil count (ANC). Its main differential diagnoses are alloimmune neutropenia $(\mathrm{AN})$, cyclic neutropenia $(\mathrm{CN})$ and severe congenital neutropenia (SCN), which are to be excluded from the beginning $(7,8)$. In $33 \%$ of our patients, no sign of infection could be identified at the time of diagnosis despite the strikingly low ANC. Due to this discrepancy between the low $\mathrm{ANC}$, which can pose the risk of potentially life-threatening infection, clinicians have to proceed immediately with an algorithmic work-up in order to exclude other etiologies of the neutropenia, after confirmation of its persistence, in order to rule out laboratory error (3). There is still debate whether or not to perform anti-neutrophil antibody screening. Walkovich and Boxer suggest that anti-neutrophil antibody screening should start in an infant who remains asymptomatic despite the persistence of low ANC (9). Bone marrow investigation may also be postponed until the result of the anti-neutrophil antibody screening is negative (8). Several methods for the anti-neutrophil antibody screening have been employed and developed, with different limitations from the point of view of their sensitivities and specificities. The International Granulocyte Immunology Workshop recommends using both the GIFT and GAT tests for diagnostic studies (4,5,8-10). It has been shown that GIFT is more sensitive than GAT. Nevertheless, there are certain alloantibody specificities, such as anti-5b, anti-NB2 and anti-9a and also autoantibodies, which are easier to be detected by the GAT. In addition, antibody titers are usually low, raising the need for the tests to be repeated. Testing for specific anti-neutrophil antibodies may be difficult to perform as well, considering the need for a sufficient number of isolated granulocytes and to the unspecific binding of IgG immune complexes to the Fc $\gamma$ receptors II and IIIb of the activated neutrophils. Conversely, it has been shown that if cells from patients are activated by inflammation and if their plasma contains large amounts of immune complexes, the elevated granulocyte-associated IgG levels may lead to false-positive results $(4,8,11,12)$. Bux et al reported the detection of granulocyte-specific antibodies in $74 \%$ of the investigated cases from a cohort of 240 tested children within the first investigation, but there was a need to repeat testing for the remainder $26 \%$ of the patients (8). Bruin et al (13) reported a rate of positivity of $80 \%$. Farruggia and Dufour found a $62 \%$ positivity rate with a single assay, but repeated assay increased the rate of positivity to $82 \%$ (5). Our findings are in accordance, showing a positivity rate of $61 \%$ at the initial testing. The limitations of the two methods can be overcome by the MAIGA (monoclonal antibody-specific immobilization of granulocyte antigen) assay (13). This technique is not routinely available and is used for the location of autoantigens $(4,11,12)$. Repeating the combined GIFT and GAT test seems to be useful, especially in challenging cases in which a bone marrow investigation may also be warranted. It has been recommended to use bone marrow examination for 
diagnosis in cases with severe infections, severe stomatitis or recurrent high fever or in the case of findings that may suggest leukemia, myelodysplastic syndromes or bone marrow failure syndromes (3). The usual finding in primary AIN is that of a reactive marrow with no morphological abnormalities and an increased myeloid to erythroid ratio. The arrest of maturation of the myeloid series has also been observed. In a minority of patients, a hypoplastic bone marrow can also be encountered, reflecting the presence of autoantibodies reactive to myeloid precursors $(4,5,14)$. In 2 of our patients, $\mathrm{BM}$ examination revealed a hypoplastic marrow. We found an incidence of $17 \%$ severe infections and a hospitalization rate of $50 \%$. In a retrospective study, Farruggia et al found a rate of $44.2 \%$ hospitalizations and only $9.6 \%$ severe infections in 157 patients (15). The use of granulocyte-colony stimulating factor (G-CSF) was necessary in $22 \%$ of the cases and was administered on-demand, as short course and in low doses. No corticosteroids or prophylactic antibiotics were used. IvIg was used in one single patient and the response was rapid and induced complete neutrophil recovery. All cohort studies have reported the use of G-CSF in primary AIN, with a rapid response rate. The effect of IvIg is reported to be good, but short lasting $(8,13)$. The time to recovery of neutrophils in different reports was between 1 and 4 years from diagnosis in the majority of patients $(3,5)$. Two patterns of recovery, continuous and intermittent, have been described, but no parameter could be identified to predict this pattern (15). The recovery curve in our study cohort showed that $\sim 90 \%$ of the patients recovered within 20 months after diagnosis. There was no statistically significant correlation between the age at diagnosis and the time to recovery; however, this could be attributed to the small number of patients in our study.

In conclusion, the results of our study support the use of the granulocyte antibody screening to confirm the diagnosis of primary AIN in order to apply a rather non-aggressive management to these patients, avoiding unnecessary use of antifungals and antibiotics and most importantly of hospitalization during febrile episodes in confirmed patients. It may also provide confidence and reassurance for the families of these children.

\section{Acknowledgements}

We would like to thank Professor Dr U. Sachs and Professor DrG. Bein from the Granulocyte Laboratory of the Zentrum fur Transfusionsmedizin und Hamotherapie of the Uniklinikum Giessen und Marburg (UKGM), Giessen, Germany for performing the granulocyte antibody screening. Professional editing, linguistic and technical assistance were performed by Irina Radu.

\section{Funding}

No funding was received.

\section{Availability of data and materials}

The datasets used and/or analyzed during the current study are available from the corresponding author on reasonable request.

\section{Author's contributions}

CJ, MS and SA conceived and designed the study. AM and EU performed the acquisition of data. CJ, AM and EU were involved in the analysis and interpretation of collected data. CJ, MS, AM and EU wrote the original draft. MS, CJ and SA were responsible for the critical revision of the manuscript's content. All authors read and approved the final manuscript.

\section{Ethics approval and consent to participate}

The approval of the local ethics committee (Ethics Committee for Scientific Research of the Emergency Hospital for Children 'Louis Turcanu') (approval no. 77/2020) was obtained prior to starting the study. Patient's parental or caregiver's consents were obtained where applicable.

\section{Patient consent for publication}

Not applicable.

\section{Competing interests}

The authors declare that they have no competing interests.

\section{References}

1. Thomas AE and Simpson LA: A step-by-step approach to paediatric neutropenia. Paediatrics and Child Health 27: 511-516, 2017.

2. Celkan T and Koç BŞ: Approach to the patient with neutropenia in childhood. Turk Pediatri Ars 50: 136-144, 2015.

3. Newburger PE: Autoimmune and other acquired neutropenias. Hematology Am Soc Hematol Educ Program 2016: 38-42, 2016.

4. Capsoni F, Sarzi-Puttini P and Zanella A: Primary and secondary autoimmune neutropenia. Arthritis Res Ther 7: 208-214, 2005.

5. Farruggia $P$ and Dufour C: Diagnosis and management of primary autoimmune neutropenia in children: Insights for clinicians. Ther Adv Hematol 6: 15-24, 2015.

6. Bux J and Chapman J: Report on the second international granulocyte serology workshop. Transfusion 37: 977-983, 1997.

7. Donadieu J, Fenneteau O, Beaupain B, Mahlaoui N and Chantelot CB: Congenital neutropenia: Diagnosis, molecular bases and patient management. Orphanet J Rare Dis 6: 26, 2011.

8. Bux J, Behrens G, Jaeger G and Welte K: Diagnosis and clinical course of autoimmune neutropenia in infancy: Analysis of 240 cases. Blood 91: 181-186, 1998.

9. Walkovich K and Boxer LA: How to approach neutropenia in childhood. Pediatr Rev 34: 173-184, 2013.

10. Dale DC: How I manage children with neutropenia. $\mathrm{Br}$ J Haematol 178: 351-363, 2017.

11. Autrel-Moignet A and Lamy T: Autoimmune neutropenia. Presse Med 43(4 Pt 2): e105-118, 2014.

12. Heinzl MW, Schönbacher M, Dauber EM, Panzer S, Mayr WR and Körmöczi GF: Detection of granulocyte-reactive antibodies: A comparison of different methods. Vox Sang 108: 287-293, 2015.

13. Bruin MC, von dem Borne AE, Tamminga RY, Kleijer M, Buddelmeijer L and de Haas M: Neutrophil antibody specificity in different types of childhood autoimmune neutropenia. Blood 94: 1797-1802, 1999.

14. Lyall EG, Lucas GF and Eden B: Autoimmune neutropenia of infancy. J Clin Pathol 45: 431-434, 1992.

15. Farruggia P, Fioredda F, Puccio G, Porretti L, Lanza T, Ramenghi U, Ferro F, Macaluso A, Barone A, Bonanomi S, et al: Autoimmune neutropenia of infancy: Data from the Italian Neutropenia Registry. Am J Hematol 90: E221-E222, 2015 